\title{
Methicillin and Inducible Clindamycin-Resistant Staphylococcus aureus Isolated from Postoperative Wound Samples
}

\author{
Abualgasim Elgaili Abdalla1,2* (D), Allam Bakheet Kabashi ${ }^{2}$, Mohamed Elnour \\ Elobaid ${ }^{2}$, Nooh Mohammed Haj Hamed ${ }^{2}$, Waddah Abozaid Modawyi ${ }^{2}$, Ayman Ali \\ Mohammed Alameen ${ }^{1,3}$ (D) Khalid Omer Abdalla Abosalif ${ }^{1,2}$ (D) and Hasan Ejaz ${ }^{1}$ (D)
}

${ }^{1}$ Department of Clinical Laboratory Sciences, College of Applied Medical Sciences, Jouf University, Sakaka - 2014, KSA. ${ }^{2}$ Department of Medical Microbiology, Faculty of Medical Laboratory Sciences, Omdurman Islamic University, Omdurman, Sudan. ${ }^{3}$ Department of Chemical pathology, Faculty of Medical Laboratory Sciences, Khartoum University, Khartoum - 11081, Sudan.

\begin{abstract}
The present study aimed to investigate the incidence of Methicillin-Resistant Staphylococcus aureus strains (MRSA) and inducible clindamycin resistant S. aureus (ICRSA) among postoperative wound infected patients. A total of $94 \mathrm{~S}$. aureus strains were isolated by conventional laboratory methods from 135 swab samples collected from post-operative wound infected patients in Khartoum State hospitals. The isolated strains were screened for MRSA by using cefoxitin disc. ICRSA strains was detected by D-test and their susceptibility to antimicrobial agents was done by modified Kirby-Bauer's disc diffusion method. Ninety-four S. aureus isolates were screened for MRSA strains, we found $\mathbf{4 2}(\mathbf{4 5 \%})$ of isolates were MRSA and 52 (55\%) of strains were methicillin-sensitive $S$. aureus (MSSA) phenotype. The incidence of ICRSA, constitutive clindamycin resistant (CCRSA) and erythromycin resistant (ERSA) strains among S. aureus isolates were $15.9 \%(15 / 94), 9 \%(8 / 94)$ and $2.12 \%(2 / 94)$, respectively. ICRSA resistant strains were slightly more frequent among MRSA, when compared with MSSA strains $(16.67 \%(7 / 42)$ vs. $15.38 \%$ $(8 / 52)$ ). In addition, $33 \%$ of ICRSA strains were found resistant to both co-trimoxazole and gentamicin, while, $23 \%$ of strains were resistant to vancomycin. This study concluded that MRSA strains was nearly accounted a half of clinical isolates, which need more attention by improving hospitals environment heath quality. ICRSA isolates were detected within both MRSA and MSSA strains and the D test must be implemented as routine susceptibility test to avoided clindamycin treatment failure.
\end{abstract}

Keywords: Staphylococcus aureus, wound, MRSA, inducible clindamycin, D-test.

*Correspondence: gasimmicro@gmail.com; +966539112018

(Received: 02 September 2019; accepted: 19 September 2019)

Citation: Abualgasim Elgaili Abdalla, Allam Bakheet Kabashi, Mohamed Elnour Elobaid, Nooh Mohammed Haj Hamed, Waddah Abozaid Modawyi, Ayman Ali Mohammed Alameen, Khalid Omer Abdalla Abosalif and Hasan Ejaz, Methicillin and Inducible Clindamycin-Resistant Staphylococcus aureus Isolated from Postoperative Wound Samples, J Pure Appl Microbiol., 2019; 13(3): 1605-1609. https://doi.org/10.22207/JPAM.13.3.33

C The Author(s) 2019. Open Access. This article is distributed under the terms of the Creative Commons Attribution 4.0 International License which permits unrestricted use, sharing, distribution, and reproduction in any medium, provided you give appropriate credit to the original author(s) and the source, provide a link to the Creative Commons license, and indicate if changes were made. 


\section{INTRODUCTION}

Staphylococcus aureus (S. aureus), a leading cause of infection in hospitals and within communities worldwide ${ }^{1}$. It is one of top most common bacterial causing wound infection $\mathrm{s}^{2}$ and other serious skin and soft tissue infections ${ }^{3} . S$. aureus is unusual pathogen that can persist in hostile environmental conditions as well as in present of antimicrobial drugs ${ }^{4}$.

Methicillin-resistant $S$. aureus (MRSA) was emerged $1960^{5}$ and still causing of significant morbidity and mortality globally ${ }^{6}$. It was reported that MRSA is responsible more than 50 of $S$. aureus associated health-care-acquired infections, including postoperative wound infection? MRSA are resistance to multiple drugs and only susceptible to glycopeptide antibiotics such as vancomycin ${ }^{8}$, nevertheless, vancomycin-resistant S. aureus (VRSA) was emerged in 2002 leading to limited treatment options ${ }^{9}$.

Clindamycin, considered as a good alternative antibiotic for treatment of MRSA infection, but inducible clindamycin (ICRSA) and clindamycin resistant strains have been reported ${ }^{10}$. Thus, the present study aimed to determine the incidence of MRSA and clindamycin-resistant $S$. aureus in patients with post-operative wound infection.

\section{MATERIALS AND METHODS}

This cross sectional study was carried out in the microbiology laboratory at faculty of Medical Laboratory Sciences (FMLS), Omdurman Islamic University during the period from October 2017 to May 2018. A total of 135 postoperative wound swabs were collected from different hospitals in Khartoum State, including Soba University Hospital, Al-Ribat University, Fedail Hospital and Yastabshiroon Hospital.

The samples were processed by using conventional laboratory methods and 94 strains of $S$. aureus were isolated. The susceptibility of $S$. aureus isolates to antimicrobial agents including cotrimoxazole $(1.25 / 23.75 \mu \mathrm{g})$, vancomycin $(30 \mu \mathrm{g})$, gentamycin $(10 \mu \mathrm{g})$, erythromycin $(15 \mu \mathrm{g})$, Clindamycin $(2 \mu \mathrm{g})$ and cefoxitin $(30 \mu \mathrm{g})$ (Bioanalyte, Turkey) was screened by modified Kirby-Bauer's disc diffusion method ${ }^{11}$. Briefly, bacterial colonies were harvested and suspended in sterile normal saline to density equilibrium to $0.5 \mathrm{McFarland}$ turbidity standard. The bacterial suspension was inoculated over entire surface of Muller Hinton agar plate (Hi-Media-India) by using sterile cotton swab. Next, antimicrobials discs were replaced in the inoculated plates and the diameter of inhibition zone was measured and interpreted after incubation at $35^{\circ} \mathrm{C}$ for $18-24$ hours, according to the manufacturer instructions. MRSA strains were identified by their resistance to cefoxitin and the isolates yielded inhibition zone $\geq 20 \mathrm{~mm}$ were considered as MRSA ${ }^{12}$.

ICRSA strains were detected by $D$ test as method previously described ${ }^{13}$. Briefly, the D-test was done by placing the erythromycin $(15 \mu \mathrm{g})$ disc in distance approximately $15-20 \mathrm{~mm}$ from clindamycin $(2 \mu \mathrm{g})$ disc on Mueller-Hinton agar plate inoculated with $S$. aureus isolated strains. Next, the plates were incubated for overnight at $35{ }^{\circ} \mathrm{C}$. After that the plates were examined for the flattened zone of inhibition around clindamycin disc, which is look like D-letter shape that indicating a positive ICRSA (Fig. 1). The isolates were resistance to both clindamycin and erythromycin considered as CCRSA, whereas, isolates were only resistance to erythromycin (ERSA) described as moderate sensitive.

Standard S. aureus ATCCC 25923 strains was used to determined quality of antimicrobial discs and laboratory procedures. Obtained data was analyzed by Statistical Package of Social Sciences Standard Program (SPSSS) version 21. 0.

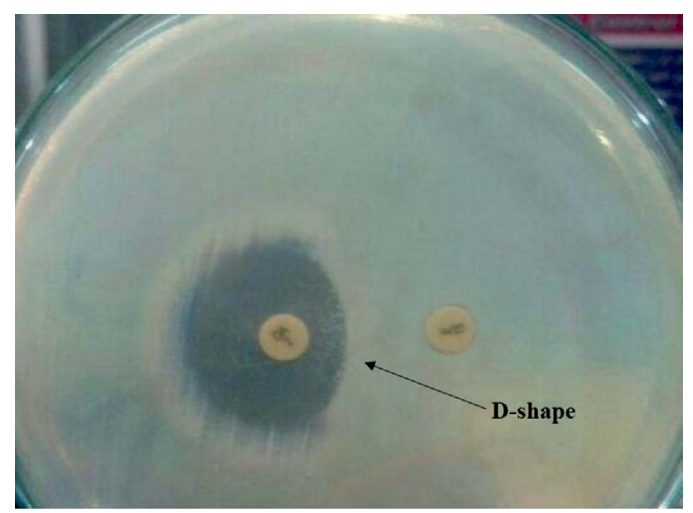

Fig. 1. Double disc test. The flattening zone of inhibition in the form of D-shape around clindamycin disc proximal to erythromycin disc, indicating for inducible clindamycin resistance. 


\section{RESULTS}

During study period 94 S. aureus strains were isolated from non-duplicate 135 postoperative wound swab samples. These isolates were screened for drug-resistant phenotypes, namely, methicillin resistant and inducible clindamycin resistant $S$. aureus and their resistance patterns to different types of antimicrobial agents.

Ninety-four of $S$. aureus isolates were screened for methicillin-resistant phenotype by using cefoxitin, we found that $45 \%(42)$ isolates were methicillin resistant strains (MRSA), while 55\% (52) were methicillin-susceptible strains (MSSA) (Table 1).

Table 1. Frequency of methicillin-resistant $\mathrm{S}$. aureus (MRSA) isolates $(n=94)$

\begin{tabular}{lcc}
\hline Phenotype & Frequency & Percentage \\
\hline MRSA & 42 & $45 \%$ \\
MSSA & 52 & $55 \%$ \\
\hline
\end{tabular}

MSSA; Methicillin susceptible S. aureus

The frequency of ICRSA, CCRSA and ERSA strains among $S$. aureus isolates were $15.9 \%$ (15/94), 9\% (8/94) and 2.12\% (2/94), respectively, (Table 2). ICRSA were slightly more frequent among MRSA when compared MSSA strains (16.67\% (7/42) vs. $15.38 \%$ (8/52) (Table 2). Fifteen ICRSA

Table 2. MLSB resistance phenotypes among S. aureus isolates

\begin{tabular}{lccc}
\hline Strains & ERSA & ICRSA & CCRSA \\
\hline S. aureus $(n=94)$ & $2.12 \%$ & $15.9 \%$ & $9 \%$ \\
MRSA $(n=42)$ & $0 \%$ & $16.67 \%$ & $5 \%$ \\
MSSA $(n=52)$ & $3.8 \%$ & $15.38 \%$ & $11.5 \%$ \\
\hline
\end{tabular}

ERSA: only resistance to resistance to erythromycin; ICRSA: Inducible clindamycin resistant S. aureus; CCRSA: constitutive clindamycin resistant $S$. aureus.

Table 3. Antimicrobial susceptibility profiling of inducible MLSB resistant $S$. aureus strains $(n=15)$

\begin{tabular}{lll}
\hline Antibiotic & Susceptible & Resistant \\
\hline Vancomycin & $73 \%(11 / 15)$ & $27 \%(4 / 15)$ \\
Gentamicin & $67 \%(10 / 15)$ & $33 \%(5 / 15)$ \\
Co-trimoxazole & $67 \%(10 / 15)$ & $33 \%(5 / 15)$
\end{tabular}

strains were tested for susceptibility to 3 different types of antimicrobial drugs, they displayed that $33 \%$ of inducible clindamycin strains were resistant to both co-trimoxazole and gentamicin, whereas, $23 \%$ of strains were resistant to vancomycin (Table 3).

\section{DISCUSSION}

Postoperative wound infection is most common type of hospital acquired infections ${ }^{14}$ which need more attention particularly with increasing the incidence of multi-drugs bacteria. S. aureus is most predominate etiology of postoperative wound infection ${ }^{15}$. MRSA is most common S. aureus strains that causing greater than a half of $S$. aureus associated healthcareacquired infection 7 . In our study 45\% (42/94) of $S$. aureus were resistant to methicillin. This prevalence rate was higher than previous reported in India $(34 \%)^{16}, \operatorname{Nepal}(25.1 \%)^{17}$, Brazil $(32 \%)^{18}$ and in Egypt $(15.8 \%)^{19}$. However, it was lower than documented in Taiwan (57.7\%) ${ }^{20}$ and in Eritrea $(59 \%)^{21}$.

Clindamycin was found to be effective for treatment of invasive MRSA and MSSA infections ${ }^{22}$. Nonetheless, emergency of in vitrofalse clindamycin susceptible $S$. aureus strains among erythromycin resistant strains may resulting in treatment failure ${ }^{23}$. This study showed that the incidence of ICRSA, CCRSA strains was $15.9 \%$ (15/94) and 9\% (8/94), respectively. In addition, ICRSA isolates were relatively more frequent among MRSA $16.7 \%$ (7/42), when compared MSSA $15.38 \%(8 / 52)$. Our findings were in concordance with the study reported by Deotate et al. noted that $14.5 \%$ of isolates were ICRSA and $3.6 \%$ were CCRSA $^{24}$. They also found that ICRSA strains were more frequent among MRSA than MSSA strains ${ }^{24}$. Prabhu et al. documented that ICRSA strains was low in prevalent compared with CCRSA strains (10\% and $18 \%$, respectively). Nevertheless, ICRSA was found to be highly frequent among MRSA than MSSA $^{25}$.

The present study demonstrate that ICRSA isolates exhibited resistance to multiple antimicrobial agents as $33 \%$ of isolates were resistance to both co-trimoxazole and gentamicin. Previous report showed that $42.86 \%$ of ICRSA strains were resistant to co-trimoxazole and $21.43 \%$ were resistant to gentamicin ${ }^{26}$. Gupta et 
al. found $44.44 \%$ of ICRSA strains were resistant to co-trimoxazole, while $27.77 \%$ were resistant to gentamicin ${ }^{27}$. Interestingly, several previous studies documented that all isolated ICRSA strains were sensitive to vancomycin ${ }^{26,27}$. However, our study revealed that $27 \%$ of isolated strains were resistance to vancomycin. This variation in antimicrobial susceptibility of isolated strains might be due to antimicrobial agents treatment policies used in each country ${ }^{28}$.

In summary the present study revealed that MRSA strains was account nearly a half of clinical of isolates, which need more attention by implementing and continuous improving hospitals infection control protocol. In addition, we found that the inducible clindamycin resistance strains were frequent within both MRSA and MSSA strains, therefore, the $D$ test must be implemented as routine susceptibility test to prevent clindamycin treatment failure.

\section{ACKNOWLEDGEMENTS}

We are grateful to the staff of Soba University Hospital, Al-Ribat University, Fedail Hospital and Yastabshiroon Hospital for assisting in data collection.

\section{CONFLICT OF INTEREST}

The authors declares that there is no conflict of interest.

\section{AUTHOR'S CONTRIBUTION}

All authors listed have made a substantial, direct and intellectual contribution to the work, and approved it for publication.

\section{FUNDING}

None.

\section{DATA AVAILABILITY}

All datasets generated or analyzed during this study are included in the manuscript.

\section{ETHICS STATEMENT}

This study does not contain any studies performed within human participants or animals.

\section{REFERENCES}

1. Lakhundi S, Zhang K. Methicillin-resistant Staphylococcus aureus: Molecular characterization, evolution, and epidemiology. Clin. Microbiol. Rev., 2018; 31(4): 20-18. https://doi.org/10.1128/ CMR.00020-18

2. Serra R, Grande R, Butrico L, Rossi A, Settimio UF, Caroleo B, Amato B, Gallelli L, de Franciscis S. Chronic wound infections: The role of Pseudomonas aeruginosa and Staphylococcus aureus. Expert Rev Anti. Infect. Ther., 2015; 13(5): 605-13. https://doi.or $\mathrm{g} / 10.1586 / 14787210.2015 .1023291$

3. Daum RS. Clinical practice. Skin and soft-tissue infections caused by Methicillin-resistant Staphylococcus aureus. N. Engl. J. Med., 2007; 357(4): 380-90. https://doi. org/10.1056/NEJMcp070747

4. Liu GY. Molecular pathogenesis of Staphylococcus aureus infection. Pediatr. Res. 2009; 65(52): 71R-77R. https://doi.org/10.1203/PDR.0b013e31819dc44d

5. Brumfitt W, Jeremy Hamilton-Miller J. Methicillinresistant Staphylococcus aureus. N. Engl. J. Med., 1989; 320 (18): 1188-96. https://doi.org/10.1056/ NEJM198905043201806

6. Lee AS, de Lencastre H, Garau J, Kluytmans J, MalhotraKumar S, Peschel A, Harbarth S. Methicillin-resistant Staphylococcus aureus. Nat. Rev. Dis. Primers, 2018; 4: 18033. https://doi.org/10.1038/nrdp.2018.33

7. Kelley M, Weber DJ, Dooley KE, Rutala WA. Healthcareassociated methicillin-resistant Staphylococcus aureus. Semin. Infect. Control, 2001; 1(3): 157-71.

8. Holmes NE, Tong SY, Davis JS, van Hal SJ. Treatment of Methicillin-resistant Staphylococcus aureus: Vancomycin and Beyond. Semin. Respir. Crit. Care Med., 2015; 36(1): 17-30. https://doi. org/10.1055/s-0034-1397040

9. McGuinness WA, Malachowa N, DeLeo FR. Vancomycin resistance in Staphylococcus aureus. Yale J. Biol. Med., 2017; 90(2): 269-281.

10. VanEperen AS, Segreti J. Empirical therapy in methicillinresistant Staphylococcus aureus infections: an up-todate approach. J. Infect. Chemother., 2016; 22(6): 351-9. https://doi.org/10.1016/j.jiac.2016.02.012

11. Hudzicki J. Kirby-Bauer disk diffusion susceptibility test protocol. 2009.

12. Fernandes CJ, Fernandes LA, Collignon P. Cefoxitin resistance as a surrogate marker for the detection of Methicillin-resistant Staphylococcus aureus. J. Antimicrob Chemother., 2005; 55(4): 506-10. https:// doi.org/10.1093/jac/dki052

13. Steward CD, Raney PM, Morrell AK, Williams PP, McDougal LK, Jevitt L, McGowan JE Jr, Tenover FC. Testing for induction of clindamycin resistance in erythromycin-resistant isolates of Staphylococcus aureus. J. Clin. Microbiol., 2005; 43(4): 1716-21. https://doi.org/10.1128/JCM.43.4.1716-1721.2005

14. Rosenthal VD, Richtmann R, Singh S, Apisarnthanarak A, K bler A, Viet-Hung N, Ramorez-Wong FM, PortilloGallo JH, Toscani J, Gikas A, Dueoas L, El-Kholy A, Ghazal S, Fisher D, Mitrev Z, Gamar-Elanbya 
MO, Kanj SS, Arreza-Galapia Y, Leblebicioglu H, Hlinkov ב S, Memon BA, Guanche-Garcell H, Gurskis V, AlvarezMoreno C, Barkat A, Mejua N, Rojas-Bonilla M, Ristic G, Raka L, Yuet-Meng. Surgical site infections, international nosocomial infection control consortium (INIC) report, data summary of 30 countries, 20052010. Infect. Control Hosp. Epidemiol., 2013; 34(6): 597-604. https://doi.org/10.1086/670626

15. Humphreys $H$, Becker K, Dohmen PM, Petrosillo $N$, Spencer M, van Rijen M, Wechsler-Fyrdצs A, Pujol $M$, Dubouix A, Garau J. Staphylococcus aureus and surgical site infections: Benefits of screening and decolonization before surgery. J. Hosp. Infect., 2016; 94(3): 295-304. https://doi.org/10.1016/j. jhin.2016.06.011

16. Pathak A, Saliba EA, Sharma S, Mahadik VK, Shah $\mathrm{H}$, Lundborg CS. Incidence and factors associated with surgical site infections in a teaching hospital in Ujjain, India. Am. J. Infect. Control, 2014; 42(1): 11-5. https:// doi.org/10.1016/j.ajic.2013.06.013

17. Adhikari RP, Shrestha S, Barakoti A, Amatya R. Inducible Clindamycin and Methicillin resistant Staphylococcus aureus in a tertiary care Hospital, kathmandu, Nepal. BMC Infect. Dis., 2017; 17(1): 483. https://doi. org/10.1016/j.ajic.2013.06.013

18. Almeida GC, dos Santos MM, Lima NG, Cidral TA, Melo MC, Lima KC. Prevalence and factors associated with wound colonization by Staphylococcus Spp. and Staphylococcus aureus in hospitalized patients in Inland Northeastern Brazil: A cross-sectional study. BMC Infect. Dis. 2014; 13(14): 328. https://doi. org/10.1186/1471-2334-14-328

19. Ahmed EF, Gad GF, Abdalla AM, Hasaneen AM, Abdelwahab SF. Prevalence of methicillin resistant Staphylococcus aureus among Egyptian patients after surgical interventions. Surg. Infect. (Larchmt). 2014; 15(4): 404-11. https://doi.org/10.1089/sur.2013.212

20. Changchien $\mathrm{CH}$, Chen SW, Chen YY, Chu C. Antibiotic susceptibility and genomic variations in Staphylococcus aureus associated with skin and soft tissue infection (SSTI) disease groups. BMC Infect. Dis., 2016; 16(1):
276. https://doi.org/10.1186/s12879-016-1630-z

21. Garoy EY, Gebreab YB, Achila OO, Tekeste DG, Kesete R, Ghirmay R, Kiflay R, Tesfu T. Methicillin-resistant Staphylococcus aureus (MRSA): Prevalence and antimicrobial sensitivity pattern among patients-a multicenter study in Asmara, Eritrea. Can. J. Infect. Dis. Med. Microbiol., 2019; 6: 8321-834. https://doi. org/10.1155/2019/8321834

22. Martonez-Aguilar G, Hammerman WA, Mason EO, Kaplan SL. Clindamycin treatment of invasive infections caused by community-acquired, Methicillin-resistant and Methicillin-susceptible Staphylococcus aureus in children. Pediatr. Infect. Dis. J., 2003; 22(7): 593-8. https://doi.org/10.1097/01.inf.0000073163.37519.ee 23. Siberry GK, Tekle T, Carroll K, Dick J. Failure of clindamycin treatment of Methicillin-resistant Staphylococcus aureus expressing inducible clindamycin resistance in vitro. Clin. Infect. Dis., 2003; 37(9): 1257-60. https://doi.org/10.1086/377501

24. Deotale V, Mendiratta DK, Raut U, Narang P. Inducible clindamycin resistance in Staphylococcus aureus isolated from clinical samples. Indian J. Med. Microbiol., 2010; 28(2): 124-6. https://doi. org/10.1086/377501

25. Prabhu K, Rao S, Rao V. Inducible clindamycin resistance in Staphylococcus aureus isolated from clinical samples. J. Lab. Physicians, 2011; 3(1): 25-7. https://doi.org/10.4103/0974-2727.78558

26. Sasirekha B, Usha MS, Amruta JA, Ankit S, Brinda $N$, Divya R. Incidence of constitutive and inducible clindamycin resistance among hospital-associated Staphylococcus aureus. 3 Biotech., 2014; 4(1): 85-89. https://doi.org/10.1007/s13205-013-0133-5

27. Gupta V, Datta P, Rani H, Chander J. Inducible clindamycin resistance in Staphylococcus aureus: A study from North India. J. Postgrad. Med., 2009; 55(3): 176-9. https://doi.org/10.4103/0022-3859.57393

28. Marston HD, Dixon DM, Knisely JM, Palmore TN, Fauci AS. Antimicrobial resistance. JAMA, 2016; 316(11): 1193-1204. https://doi.org/10.1001/jama.2016.11764 